\title{
Traumatic rupture of the thoracic aorta: diagnosis on fibreoptic bronchoscopy
}

The diagnosis of thoracic aortic rupture can be difficult, especially in the presence of other life-threatening injuries. We present a case in which the presence of major intraabdominal trauma shifted clinical attention away from the mediastinum. During bronchoscopy, which was performed to investigate high intraoperative airway pressures, unexpected tracheal and carinal compression were discovered. Thoracic aortography revealed aortic rupture distal to the left subclavian artery. Successful repair was subsequently achieved.

Le diagnostique d'une rupture de l'aorte thoracique peut être difficile particulièrement en présence d'autres traumatismes potentiellement mortels. Nous présentons un cas où la présence d'un traumatisme intra-abdominal majeur a détournél'attention clinique portée habituellement au médiastin. Une compression imprévue de la trachée et de la carène a été découverte pendant la bronchoscopie, laquelle a été faite afin de trouver la cause d'une pression des voies aériennes élevée. Une aortographie thoracique a révélé une rupture aortique distale à l'artère sousclavière gauche. La rupture aortique fut par la suite réparée avec succès.

Tracheobronchial compression is a well-recognized complication of thoracic aortic aneurysm. ${ }^{1,2}$ However, tracheal and mainstem bronchial compression have not been described with traumatic rupture of the aorta.

We present a case of multiple trauma in which aortic

Key words

ARTERIES: aorta, rupture;

EQUIPMENT: tubes, endobronchial, bronchoscope, fibreoptic.

From the Departments of Anaesthesia and Surgery, Sunnybrook Health Science Centre and the University of Toronto.

Address correspondence to: Dr. D. Oxorn, Department of Anaesthesia, Sunnybrook Health Science Centre, 2075

Bayview Avenue, Toronto, Ontario, Canada M4N 3 M5. Accepted for publication 4 th November, 1991.
Donald Oxom MD CM FRCPC, Giuseppe Pagliarello MD FRCSC injury was not initially suspected. Fibreoptic bronchoscopy performed to investigate high intraoperative airway pressures revealed lower tracheal compression and a markedly distorted carina. Thoracic aortography disclosed aortic disruption distal to the left subclavian artery. Subsequent primary repair was successfully accomplished.

\section{Case report}

The patient, a 65-yr-old white man, was the driver of a car that was struck broadside on the driver's side. Injuries included fractures of his left fifth and sixth ribs, a left haemothorax, bilateral pulmonary contusions, a ruptured left hemidiaphragm, and a lacerated spleen. There were no obvious signs of pelvic or extremity injury. Initial cervical spine $x$-rays suggested the possibility of a fracture at the $\mathrm{C}_{6}$ level. The patient was haemodynamically stable, awake and alert. Following nasotracheal intubation with a \#7.0 endotracheal tube, and insertion of a left chest tube, the patient was transferred to the Sunnybrook Health Sciences Centre, a level one trauma centre, for repair of the left hemidiaphragm and splenectomy.

Anaesthesia was induced with thiopentone, and maintained with isoflurane in oxygen, and intermittent boluses of fentanyl. Muscle relaxation was achieved with pancuronium bromide. During the first two hours of the procedure, the peak airway pressure steadily increased, from 40 to 75 $\mathrm{cm} \mathrm{H}_{2} \mathrm{O}$. Chest auscultation revealed bilateral inspiratory and expiratory wheezes. Because no cause could be readily identified, a $4 \mathrm{~mm}$ bronchoscope was passed through the nasotracheal tube. Severe mid-tracheal compression was evident; the bronchoscope was advanced further, and revealed a grossly distorted carina, with compression of the left mainstem bronchus (Figure 1). The admission chest $x$-ray was reassessed, and thought to show mediastinal widening (Figure 2). Because the nasotracheal tube could not be advanced, and the larynx could not be visualized on direct laryngoscopy, a tracheostomy was performed, with reduction of the peak airway pressure to $25 \mathrm{~cm} \mathrm{H}_{2} \mathrm{O}$. Following completion of surgery, the patient was transferred to the radiology suite. A contrast enhanced CT scan revealed a leak from the thoracic aorta, and a new right pleural effusion (Figure 3); chest tube insertion con- 


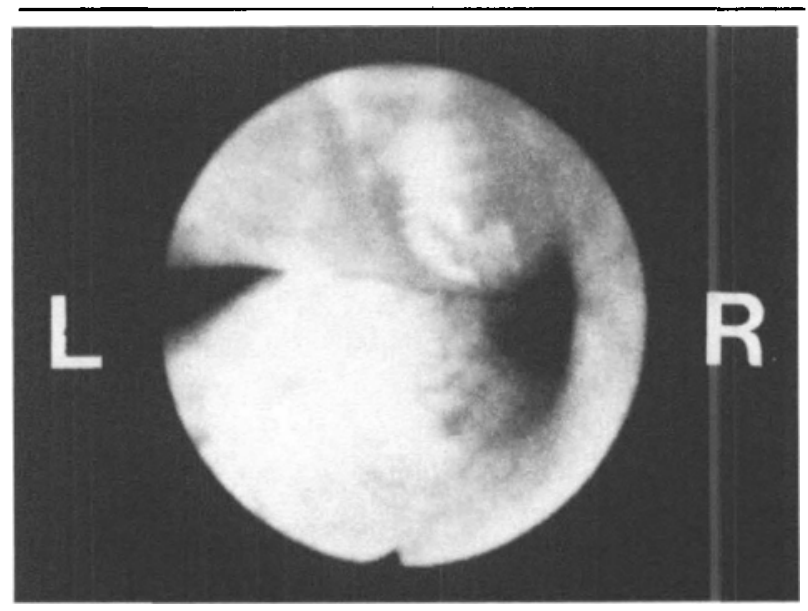

FGURE I The carina. Gross distortion, with compression of the left main stem bronchial orifice.

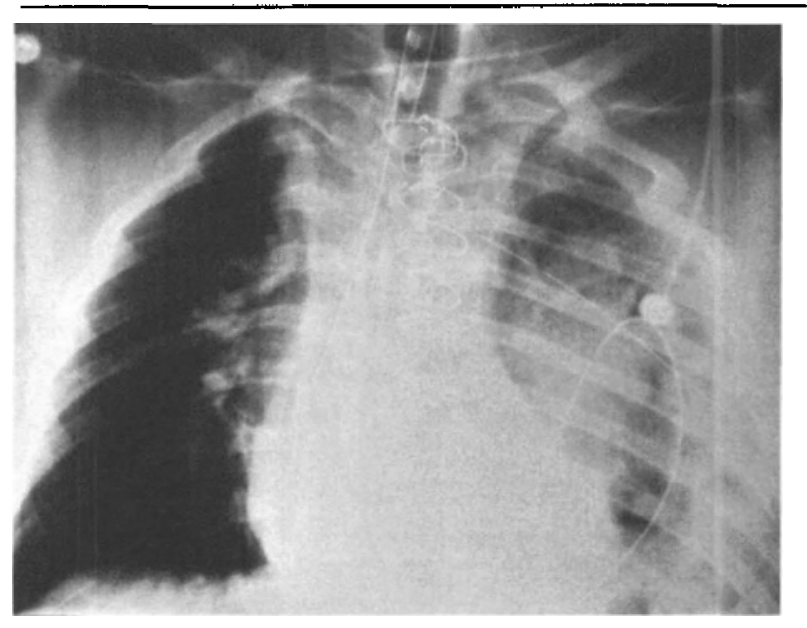

FIGURE 2 Admission chest $x$-ray. Note the widened mediastinum, intrathoracic nasogastric tube, left haemothorax, left pulmonary contusion, and blunting of aortic arch. Sternal wires are from a previous coronary artery bypass graft.

firmed that it was a haemothorax. Arch aortography demonstrated a tear distal to the left subclavian artery.

The patient was subsequently taken to the operating room. Anaesthesia was induced and maintained with fentanyl and isoflurane in oxygen. Pancuronium was used for muscle relaxation. Primary aortic repair was accomplished through a left thoracotomy; intraoperative collapse of the left lung was accomplished with an 8 Fr Fogarty catheter (American Edwards Laboratories), inserted through the lumen of the tracheostomy tube into the left mainstem bronchus, and thereafter inflated.

Hypertension during aortic cross-clamping was controlled with intravenous nitroprusside. No difficulties were

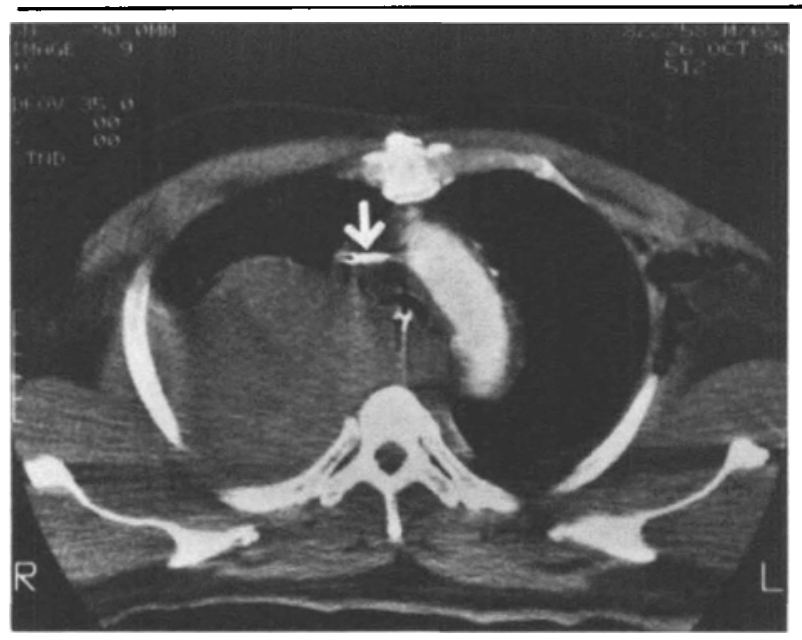

FIGURE 3 Contrast enhanced CT scan. The cut is at the level of the aortic arch. The arrow indicates the leak of contrast. A right-sided pleural effusion is present.

encountered with oxygenation during the period of onelung anaesthesia.

The patient's postoperative course was complicated by respiratory failure and deep vein thrombosis. He was discharged in excellent condition 32 days after admission.

\section{Discussion}

The presentation and management of tracheobronchial compression from thoracic aortic aneurysms has been well described. ${ }^{1,2}$ Caution has been advised in the advancement of endobronchial tubes, lest the aneurysmal sac be ruptured. ${ }^{3}$ In a review of 114 cases of blunt chest trauma with thoracic aortic rupture, no mention was made of airway compression. ${ }^{4}$ Our patient is unique in that the false aneurysm impinged on the trachea and carina sufficient to make ventilation difficult.

Approximately $5 \%$ of patients admitted to our institution with blunt chest trauma have thoracic aortic injury. ${ }^{5}$ The diagnosis of acute thoracic aortic rupture may be difficult, as these patients often have coexistent lifethreatening injuries to other vital organs. Fifteen percent of the initial survivors live long enough to reach the hospital for diagnosis and treatment and $90 \%$ of those who remain undiagnosed may not survive four months. ${ }^{6}$

The radiological signs of traumatic rupture of the thoracic aorta are well described (Table). ${ }^{7}$ Although no one sign has been found to be totally predictive, ${ }^{8}$ Kirshner et al. ${ }^{9}$ suggest that if the ratio of the mediastinal to the total chest width at the level of the aortic arch is greater than 0.28 , aortic rupture is likely. In our patient, the ratio was 0.36 . Ayella ${ }^{10}$ believes that the superior mediastinum cannot be evaluated with a supine chest film, as too many 
TABLE Abnormalities on plain chest radiography in traumatic aortic rupture

Widened mediastinum

Loss of aortic sharpness

Enlarged or abnormal aortic contour

Obliteration of aortic-pulmonary window

Downward displacement of left mainstem bronchus

Deviation of the trachea to the right

Deviation of the nasogastric tube to the right

Left apical cap

Left haemothorax

false-positive aortic ruptures will be diagnosed. The presence of a ruptured diaphragm diverted our attention away from the possibility of a ruptured aorta. When difficulty was encountered with mechanical ventilation and bronchoscopy was performed, the initial chest $x$-ray was reassessed, and a number of suggestive elements were noted (Figure 1). Angiography confirmed the presence of an aortic tear.

Because of the presence of a fresh tracheostomy, and distorted bronchial anatomy, double lumen endotracheal tube insertion and standard bronchial blocker placement ${ }^{11}$ were deemed inappropriate. Placement of the blocker through the tracheostomy tube circumvented these problems. 12

In view of this case, and previous reports, it would appear prudent to include fibreoptic bronchoscopy as part of the preoperative workup of patients presenting with traumatic injuries of the thoracic aorta. Delineation of airway anatomy may aid in the proper selection of endotracheal and endobronchial tubes, and their safe placement.

\section{References}

1 Kimitoshi N, Komatsu T, Yasuhiro S, Takeuchi E, Abe T. Severe tracheal compression caused by a false aneurysm arising from the ascending aorta: successful airway management using induced hypotension and bronchoscopy. Anesthesiology 1990; 73: 1047-9.

2 MacGillivray RG. Tracheal compression caused by aneurysms of the aortic arch. Anaesthesia 1985; 40: 270-7.

3 Cohen JA, Denisco RA, Richards TS, Staples ED, Roberts AJ. Hazardous placement of a Robertshaw-type endobronchial tube. Anesth Analg 1986; 65: 100-1.

4 Cowley RA, Turney SZ, Hankins JR, Rodriguez A, Attar S, Shankar BS. Rupture of thoracic aorta caused by blunt trauma. A fifteen year experience. $J$ Thorac Cardiovasc Surg 1990; 100: 652-61.

5 Devitt JH, McLean RF, Koch JP. Anaesthetic management of acute blunt thoracic trauma. Can J Anaesth 1991; 38: 506-10.
6 Parmley LF, Mattingly TW, Manion WC. Non penetrating injury of the aorta. Circulation 1958; 17: 1086-101.

7 Shulman HS, Samuels TH. The radiology of blunt chest trauma. J Can Assoc Rad 1983; 34: 204-17.

8 Mirvis SE, Bidwell JK, Buddemeyer EU. Value of chest radiography in excluding traumatic rupture. Radiology 1987; 163: 487-93.

9 Kirshner R, Seltzer S, D'Orsi C, DeWeese JA. Upper rib fractures and mediastinal widening: indications for aortography. Ann Thorac Surg 1983; 35: 450-4.

10 Ayella RJ. Radiologic Management of the Massively Traumatized Patient. Baltimore: Williams and Wilkins, 1978.

11 Ginsberg RJ. New technique for one lung anesthesis using an endotracheal blocker. J Thorac Cardiovasc Surg 1981; 82: 542-6.

12 Oxorn DC. Use of a fiberoptic bronchoscope to assist placement of a Fogarty catheter as a bronchial blocker. Can J Anaesth 1987; 34: 427-8. 